\title{
LOS SOPORTES DE PUBLICIDAD EXTERIOR COMO ELEMENTO DE EXHIBICIÓN ARTÍSTICA EN EL ARTE ESPAÑOL DE VOCACIÓN CRÍTICA
}

\author{
Ana García Alarcón \\ Univ. Complutense, Dpto. Historia del Arte, colaboradora honorífica
}

\section{Resumen}

Este artículo toma como punto de partida las relaciones entre el arte y la publicidad para analizar cómo, desde las artes visuales y la institución artística, se utilizan muchos recursos propios de la industria publicitaria. Nos centraremos en los soportes de publicidad exterior y en cómo éstos son empleados como elemento de exhibición artística. Al salirnos de los escenarios habituales para mostrar el arte contemporáneo, estos lugares nos ofrecen la posibilidad de llegar a un público más amplio. Estos contenedores para la publicidad se transfiguran por un tiempo en espacios para el arte, pasando a acoger obras con una intencionalidad muy dispar. Este tipo de intervenciones se articulan desde la inserción (mediante el alquiler de estos espacios), pero también a través de la usurpación, siendo muchos los creadores que intervienen en ellos sin pedir permiso. Reflexionaremos sobre el potencial de las imágenes y sobre la saturación que éstas pueden crear en nuestro día a día.

\section{Palabras clave: ARTE CONTEMPORÁNEO ESPAÑOL; ARTE CRÍTICO; PUBLICIDAD}

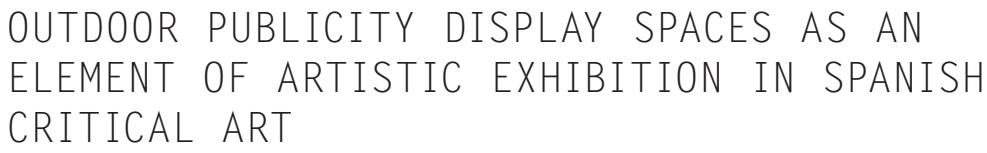

\section{Abstract}

The starting point of this article is the relationship between art and advertisement that leads us to analyze how visual arts and Artistic Institution use some resources from the Publicity Industry. We focus on outdoor publicity displays and how they are used as an element of artistic exhibition. Looking further ahead than the normal context to show the contemporary art, these spaces offer us the possibility to reach a wide public. These 'publicity containers' become display art spaces temporary, which welcome artworks with a very different intention. These kind of artistic interventions not only work through the insertion (renting these publicity displays), but also through misappropriation, being many artists who use without permission these spaces. We will think about the potential of these images (form the advertisement and form the visual art) and about how overwhelming they can be in our everyday life.

Keywords: CONTEMPORARY SPANISH ART; CRITICAL ART; ADVERTISEMENT

\footnotetext{
García Alarcón Ana. 2018. “Los soportes de publicidad exterior como elemento de exhibición artística en el arte español de vocación crítica“. AusArt 6(2): 245-257. D0I:10.1387/ausart.20384
}

\section{AUSART}




\section{INTRODUCCIÓN}

Vivimos en un mundo repleto de imágenes en el que los mass media y la publicidad inundan nuestro día a día. Cuando nos paramos a pensar en lo intrusiva que puede llegar a ser la publicidad nos damos cuenta que ya forma parte de nuestra vida y que, en cierto modo, ha condicionado nuestros hábitos de comportamiento. Al adentrarnos en cuestiones ligadas al universo publicitario no podemos olvidar que arte y publicidad van de la mano desde los inicios de la publicidad, bebiendo ésta de las fuentes del arte, sirviéndose de sus técnicas y creativos pero también ofreciendo nuevos soportes y a atractivos que, sin duda, hicieron que muchos de los artistas pasaran a colaborar y a formar parte, de alguna manera, de esta emergente industria. Esto es algo que continúa hasta nuestros días y que, en este artículo, tomaremos como punto de partida para adentrarnos en cómo funciona dentro de nuestro campo de estudio: el arte español actual de vocación crítica.

Partimos de estos vínculos existentes entre estos dos lenguajes para así analizar el comportamiento de las artes visuales en relación con los soportes publicitarios y cómo éstos lugares (o no lugares) se convierten en espacio de exhibición artística. Son muchos los creadores que hoy se sirven de estos canales propios de la publicidad para exponer su trabajo. Además, desde la institución artística, se ha asumido el mobiliario urbano como complemento a la exposición. Son muchos los centros de arte o museos que, dentro de su espectro de posibilidades, valoran la opción de sacar el trabajo artístico al exterior, siendo conscientes del potencial que esto puede llegar a tener. Analizaremos cómo los artistas se sirven de estos espacios para lanzar sus mensajes, logrando llegar a un público que normalmente no visita el museo o la galería, pero también cuestionaremos aspectos en este sentido. La valla, el mupi o la marquesina -que normalmente sirve como elemento de difusión de un producto de nuestro sistema-, se transforma por un tiempo en contenedor artístico, adquiriendo un rol que puede tanto potenciar como desactivar la visibilidad de un mensaje artístico. Nos adentraremos en cómo el arte de vocación crítica se inserta en estos soportes para cuestionar y revisar su efectividad y el alcance a los públicos. Cómo las instituciones los han asumido no sólo como lugar donde mostrar la información de la exposición a nivel de comunicación sino como parte de la obra del artista, como otra posibilidad expositiva. En este sentido podemos hablar de una pequeña grieta en el sistema, desde donde el artista se adentra para introducirse en un mecanismo que es capaz de generar lenguajes y diálogos de una dimensión mayor que la que crea el propio sistema del arte, pero desde dentro de él a su vez. 


\section{ICONOSFERA PUBLICITARIA VERSUS ARTES VISUALES}

La publicidad, desde sus inicios, ha necesitado del arte para poder comenzar a dar sus primeros pasos, generándose un diálogo y un intercambio continuado entre ambos lenguajes. No podemos obviar que la publicidad moderna supuso un enorme atractivo para muchos creadores, que vieron en ella múltiples posibilidades hasta el momento impensables dentro del campo de las artes plásticas. Los artistas no sólo estudiaron sus técnicas, sino que pasaron a formar parte de esta entonces incipiente industria llegando a trabajar para ella en campañas y proyectos específicos en este sentido'. Recordemos la obra de Ramón Casas y sus carteles para marcas como Anís del Mono o Codorniu, o los carteles republicanos de Josep Renau, un referente para entender la naturaleza y el comportamiento de la cultura contemporánea española (Brihuega 1995b, 22-37) $)^{2}$. Sin olvidar el afamado toro de Osborne de Manolo Prieto que hoy continúa inundando los paisajes españoles. Este trabajo fue un diseño encargado a Prieto en 1956 como director de la campaña del brandi, comenzando a colocarse años más tarde, en 1958, las primeras vallas fabricadas en madera que, en el año 61 , son sustituidas por otras chapas de metal, aumentando el tamaño de estos soportes ${ }^{3}$.

Jaime Brihuega escribe: "La silueta del toro de Manolo Prieto ha ido emergiendo en el horizonte, absorta y ajena a sus propias contingencias publicitarias, eucarística en su transubstanciación en trozo metafísico del alma tribal y, a la postre, huérfana de las verdaderas coordenadas umbilicales que la unían a la imaginación y a las manos de su creador" (1995a, 30).

Los guiños a la publicidad desde las artes plásticas y visuales son múltiples; podríamos escribir un artículo solamente con citas y ejemplos en este sentido comenzando desde finales del sigo XIX hasta llegar a nuestros días. Los paisajes configurados por carteles y anuncios se veían reflejados en las pinturas de Marquet y Dufy Carteles de Trouville (1906); en algunas obras cubistas como Paisaje de los carteles (1912) de Picasso y Au bon marché (1914) de Juan Gris. Libros de Ródchenko (1925) ha sido tomada como imagen que sirve a la perfección como insignia publicitaria para representar imaginarios vinculados a la revolución, utilizándose en múltiples ocasiones por tanto desde el campo de las artes visuales como desde la música o de la publicidad. Una muestra de ello es Indignaos del colectivo CERREC (2011)4. 
En la década de los 70 , son muchos los artistas que comienzan a insertarse en los soportes publicitarios desde una perspectiva más cercana a la contemporánea como sucede con algunas intervenciones de Daniel Buren o, ya en los años 80 y 90, las propuestas de artistas como Martha Rosler, Barbara Kruger, Jenny Holzer o Guerrilla Girls. Holzer, preocupada por el paisaje mediático, introdujo sus consignas en los luminosos; Barbara Kruger proyecta campañas de igualdad de género sirviéndose, desde el fotomontaje, de anuncios publicitarios; Guerrilla Girls se insertan en soportes de publicidad exterior para lanzar sus campañas desde las artes visuales en las que reivindican el papel de la mujer artista dentro de un mundo del arte eminentemente blanco y masculino ${ }^{5}$.

Las inserciones en soportes propios de la publicidad se convierten en una constante, pero también lo son la apropiación de recursos y herramientas propias del universo publicitario. Nicola Constantino nos ofrece un jabón corporal elaborado de grasa humana de la propia artista, la cual, nos invita a bañarnos con ella con su Savon de corps (2004); mientras Francesco Vezzoli representa metafóricamente la lucha a la que asistimos en la sociedad contemporánea a través de la rivalidad de dos mujeres que pelean por conseguir a cualquier precio la fragancia Greed (GREED, a new fragance by Francesco Vezzoli, 2009). Vemos cómo el spot publicitario es decontextualizado y mostrado en un espacio destinado a la exhibición artística.

\section{IMÁGENES PARA LA FELICIDAD. LOS MASS MEDIA COMO ELEMENTOS GENERADORES DE UN DISCURSO HEGEMÓNICO}

La apropiación de las estrategias publicitarias se convierte en un elemento muy recurrente desde las artes visuales. Son muchos los creadores que toman marcas preexistentes para revisarlas, recontextualizarlas y dotarlas de nuevos mensajes y valores, generando obras derivadas, "nuevas marcas" o nuevos imaginarios desde una mirada crítica. En este sentido es relevante el trabajo de PSJM Grandes Marcas (2006-2007) o Marcas Ocultas (2006), proyectos en los que se establece una crítica al sistema a través de sus logotipos. El colectivo DEMOCRACIA con Ser y Durar (2011) (Fig. 1) propone una imagen que es asociada a un proyecto artístico a través de tipografías propias de un logotipo, algo que vemos en muchos de sus proyectos y que se repite en obras como Drama (2014) de Avelino Sala. 
Son muchas las vías de apropiación de las estrategias publicitarias desde las artes visuales en el arte contemporáneo ${ }^{6}$. La campaña publicitaria es tomada desde las artes visuales como una contracampaña, a través de una mirada crítica y una búsqueda de nuevas lecturas desde estos lenguajes, los publicitarios, que, en muy poco tiempo han logrado llegar al gran público y ser un elemento que es, incluso, familiar

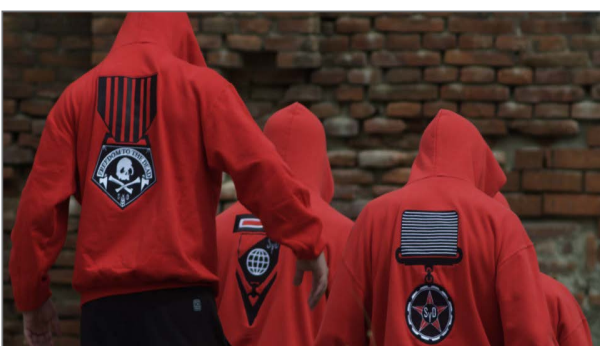

Figura 1 para todos nosotros.

El universo publicitario ha adquirido en un periodo de tiempo muy breve un gran potencial, logrando irrumpir en nuestra cotidianidad. La omnipresencia de los medios de comunicación y la cantidad ingente de anuncios publicitarios que consumimos a diario, hace que muchos artistas tomen estos imaginarios colectivos como fuente para realizar sus producciones artísticas que representan la iconografía cultural de su tiempo. Los mass media promueven un mundo paralelo a través de imágenes y recursos que proyectan una serie de necesidades, gustos e ideologías hegemónicas a imitar. En este sentido, debemos considerar que este medio está programado y guiado por el sistema y sus intereses, reflejando así, a través de estos mecanismos, las vías para alcanzar la 'felicidad plena'. Un espejismo de la vida capitalista.

Estos medios son una herramienta con una enorme influencia en la sociedad, sirviendo como estructuras de transmisión de información, ejerciendo como mecanismos de control'. Baudrillard señala: "La TV nos contempla, la TV nos aliena, la TV nos manipula, la TV nos informa..." ([1978] 2014, 63). Denis McQuail (1991) nos adelanta que existe una dependencia implícita con el sistema político, encargado de financiar las actividades de los medios de comunicación, siendo este acto un condicionante para una gran parte de la información que estos espacios emiten, sea de la naturaleza que sea. Al estar frente a los medios de masas debemos conocer este componente y tener presente que nos están mostrando una realidad fragmentada. Tienen la capacidad de mostrarnos 'su' verdad, ofreciendo una porción de la realidad que tiene como objetivo domesticar a un público que consume sus mensajes. Esta colectividad teledirigida consume y asimila información, aunque en ocasiones la rechace ya que no podemos olvidar que existe una masa crítica que analiza estos contenidos. 
Además, las mitologías publicitarias tienen la capacidad de generar mundos soñados, escenarios que nos ofrecen deseos e ilusiones que nos hacen evadirnos por un instante en nuestra realidad; introduciéndonos, de una forma totalmente inconsciente, en el mundo del consumo. Mundos que podrían formar parte de simulacro del que nos habla Jean Baudrillard (1978), que pertenece a una simulación en la que los medios de masas nos inoculan ideologías a través de metonimias que de alguna manera aluden al sentido de la vida. Vivimos un momento en el que estos espejismos generan un espacio de confort del que no queremos salir porque comenzamos a sentirnos felices en él, como señala Eloy Fernández Porta (2012).

En cierto sentido, nos adentramos a un imperio de los afectos en el que se genera una atracción incondicional en la que son muchos los creadores que, consientes del potencial que estos medios pueden llegar a tener, deciden servirse de sus herramientas de comunicación para, desde dentro, lanzar mensajes críticos contra el sistema que normalmente se sirve de ellos: mercado y Estado. Estamos hablando de publicidad, pero también de propaganda, ya que estas formas de vida hegemónicas que nos muestran los mass media son dirigidas por un sistema de poder en el que tanto mercado como Estado juegan un papel fundamental.

\section{CONTEXTOS. SOPORTES DE PUBLICIDAD EXTERIOR COMO ELEMENTOS DE EXHIBICIÓN ARTÍSTICA}

Los lugares para mostrar el entramado que hay detrás de una campaña publicitaria son, en cierto modo, el espacio final, pero también el visible. Estos canales se hacen visibles a través de las Redes Sociales e Internet, periódicos, revistas, en un SMS o un correo electrónico, mientras escuchamos la radio... Son los soportes de publicidad exterior los que centrarán nuestra atención como elementos de exhibición artística, los ubicados en las ciudades. Estos espacios se materializan en forma de vallas, mupis, marquesinas, cartelería, pantallas, inserciones en el transporte público, papeleras y otros elementos del mobiliario urbano de una ciudad (Baladrón, Martínez \& Pacheco 2007).

Los soportes de publicidad exterior, al estar inscritos en el espacio urbano, tienen un atractivo añadido. Su accesibilidad y su potencial los convierten en 
elementos que son capaces de llegar a todo el mundo de una forma rápida, fácil y directa. A diferencia de los lugares habituales para la exhibición artística, estos contenedores tienen una expansión sorprendente; esto hace que muchos artistas se sirvan de ellos desde la apropiación y la usurpación, o realizando inserciones de una forma normalizada, del mismo modo y por las mismas vías que lo hace una agencia: a través de la institución artística. En ocasiones, la gestión de estos soportes se realiza desde museos, bienales, ferias o centros de arte, siendo cada vez más usual el dejar de utilizar estos lugares como soporte para la comunicación de una exposición para albergar la obra artística.

Estos escenarios de difusión ocupan lugares privilegiados, convirtiéndose en un contenedor idóneo para mostrar arte. También son muchos los artistas que los intervienen sin pedir permiso. Por otro lado, estos soportes pueden llegar a interpretarse como una oportunidad para llegar a un público más amplio y un contexto que se encuentra fuera del mundo del arte, donde el espectador no tiene una mirada condicionada como sucede cuando entra a un espacio de arte. Sin embargo, no debemos olvidar que estos lugares se sitúan en un escenario repleto de mensajes visuales donde estas obras tienen que competir con anuncios publicitarios corriendo el riesgo de ser anulados o invisibilizados presentándose la publicidad como un peligroso rival.

\section{INSERCIÓN VERSUS USURPACIÓN}

La inserción se presenta como forma normalizada de introducirse en estos lugares para la publicidad. Es tan sencillo como pagar el precio establecido por anunciarte dentro de un soporte determinado, importe que dependerá de la duración, de su formato y de su ubicación. Tan sólo hay que contactar con la empresa encargada de hacer estas gestiones y establecer un calendario y unas condiciones.

Muchos ayuntamientos e instituciones disponen de un porcentaje para la comunicación de sus campañas, y también son cada vez más los museos y centros de arte que deciden alquilarlos tanto como elementos de comunicación como para mostrar trabajos artísticos que dialoguen con su entorno. En esta línea, recientemente podíamos encontrar en las calles de Valencia autobuses con el mensaje 'democraticemos la democracia', un proyecto de 
Daniel García Andújar (Fig. 2) con motivo de su exposición individual en el Centre del Carme Cultura Contemporània (2018). Estos mensajes se podían leer en 2011 en la costa del levante insertados en otro elemento de publicidad exterior, una avioneta (Fig. 3). Este soporte podemos encontrarlo en las playas anunciando formas de ocio como un restaurante o un parque acuático pero, en esta ocasión, contextualizado en un momento de eclosión del 15M, nos invitaba a pensar en torno a una cuestión latente en el ambiente: el sistema democrático español.

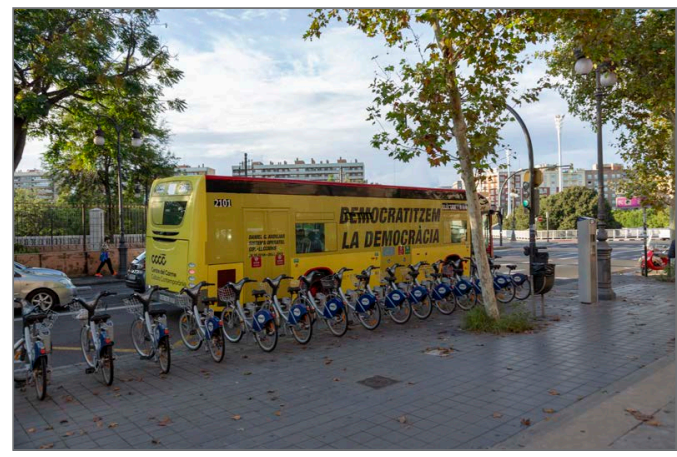

Figura 2.

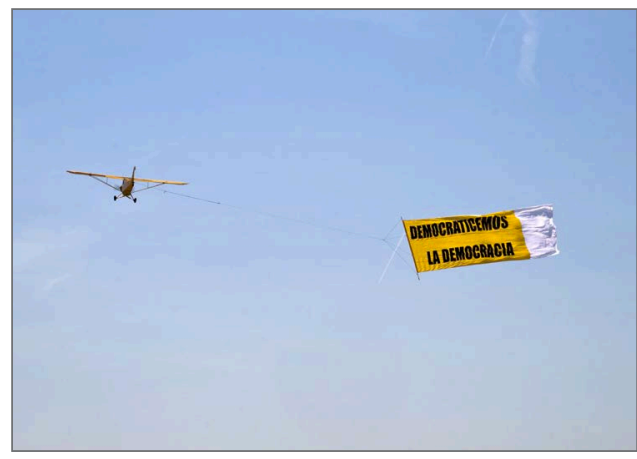

Figura 3

Rogelio López Cuenca a través de su práctica artística se sirve con regularidad de estos elementos de publicidad exterior. En Total (2006) (Fig. 4), parte de la campaña del Ministerio de Medio Ambiente del año 2005 para, desde la ironía, lanzar una crítica directa a una problemática en la que estaba, y continúa, inmerso nuestro país. "El Total es lo que cuenta", rezaba la campaña original, mientras en las piezas de López Cuenca leemos lemas como "Total, por un megapuerto industrial de nada...", "Total, por unos campitos de golf...", "Total, por una montaña menos y unos pocos millones de euros más...", "Total, por otro edificio singular...", "Total, por una valla, más...". Las intervenciones estaban enmarcadas en la I Bienal de Arquitectura y Paisaje de las Islas Canarias en el año 2006. Estos carteles se insertaban en los mupis y marquesinas de la ciudad para analizar, desde estos espacios ubicados en las calles, las problemáticas ligadas al boom inmobiliario desde dentro, desde un escenario institucional, una bienal de arte contemporáneo. La especulación política, la inmigración o la política turística y territorial se ofrecen de una forma en la que podrían llegar a pasar desapercibidas e incluso confundirse con su campaña real pero, si nos detenemos vemos cómo las imágenes que la acompañan y sus mensajes son totalmente diferentes. Esto hace que estos soportes adquieran en este tipo de acciones un componente añadido al permitir lanzar estos mensajes, camuflados por las estrategias propias de la publicidad, en 
un contexto cotidiano, donde el público no va con una predisposición a ver arte sino que simplemente lo lee del mismo modo que otro tipo de campañas publicitarias.

Estas inserciones son muy frecuentes en la práctica artística de Rogelio López Cuenca. En Saharawhy (2012) (Fig. 5), junto a Elo Vega, vuelven a emplear procedimientos propios de la industria publicitaria. García Andújar, en Not Found 1000 casos de estudio (2014), inserta mensajes de error informáticos en lugares destinados a mensajes comerciales; PSJM, con Capitalismo D.E.P. (2009), se introduce en las marquesinas de autobuses de la ciudad de Cuenca en el marco del Festival Ingráfica, del mismo modo que lo hacen con su campaña Marx® (2008) en los mupis de las calles circundantes al museo Laboral de Gijón y el Centro Atlántico de Arte Moderno de Las Palmas de Gran Canaria. DEMOCRACIA, en Subtextos (2009-2010) y Sin Estado (2009), vuelven a introducirse en estos contextos, siendo una práctica muy frecuente para muchos de estos creadores que conciben parte de su producción artística como una obra para mostrarse en el exterior del espacio habitual de exhibición artística.

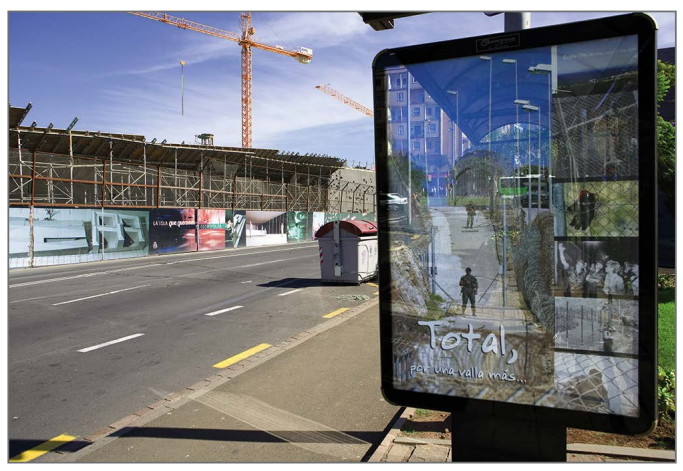

Figura 5.

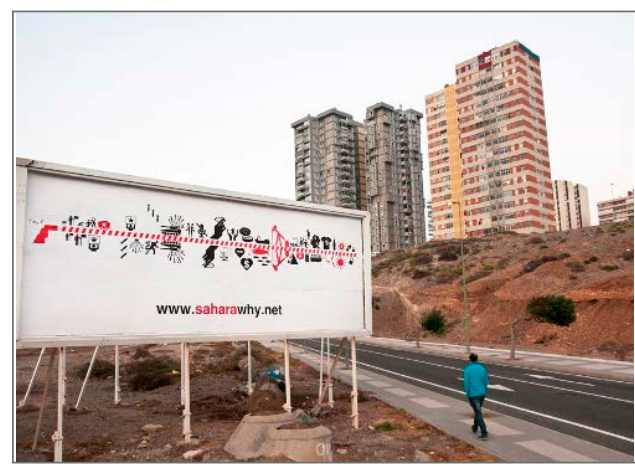

Figura 6

Los soportes publicitarios también son empleados desde otra perspectiva: mediante pegadas de carteles o inserciones sin permiso en estos contextos de publicidad exterior. Menos es menos (Noaz, 2013), Estado Asesino, Libertad para los Muertos (DEMOCRACIA, 2010), Acciones Urbanas Absurdas (Left Hand Rotation, 2009-2013), You are a commodity (PSJM y Marc Bijl, 2010) o Gentrification (DosJotas, 2015) se inscriben en esta línea. En Any resemblance to reality (Fig. 6) (Ámsterdam y Nueva York, 2012-2014), Dos Jotas se introduce en espacios publicitarios para lanzar sus contracampañas donde anunciaba: "cualquier parecido con la realidad es pura coincidencia". Estos 
mensajes sustituyen por un tiempo los anuncios de las calles para invitarnos a reflexionar sobre cuestiones ligadas a escenarios colectivos y a nuestro contexto más próximo ${ }^{8}$.

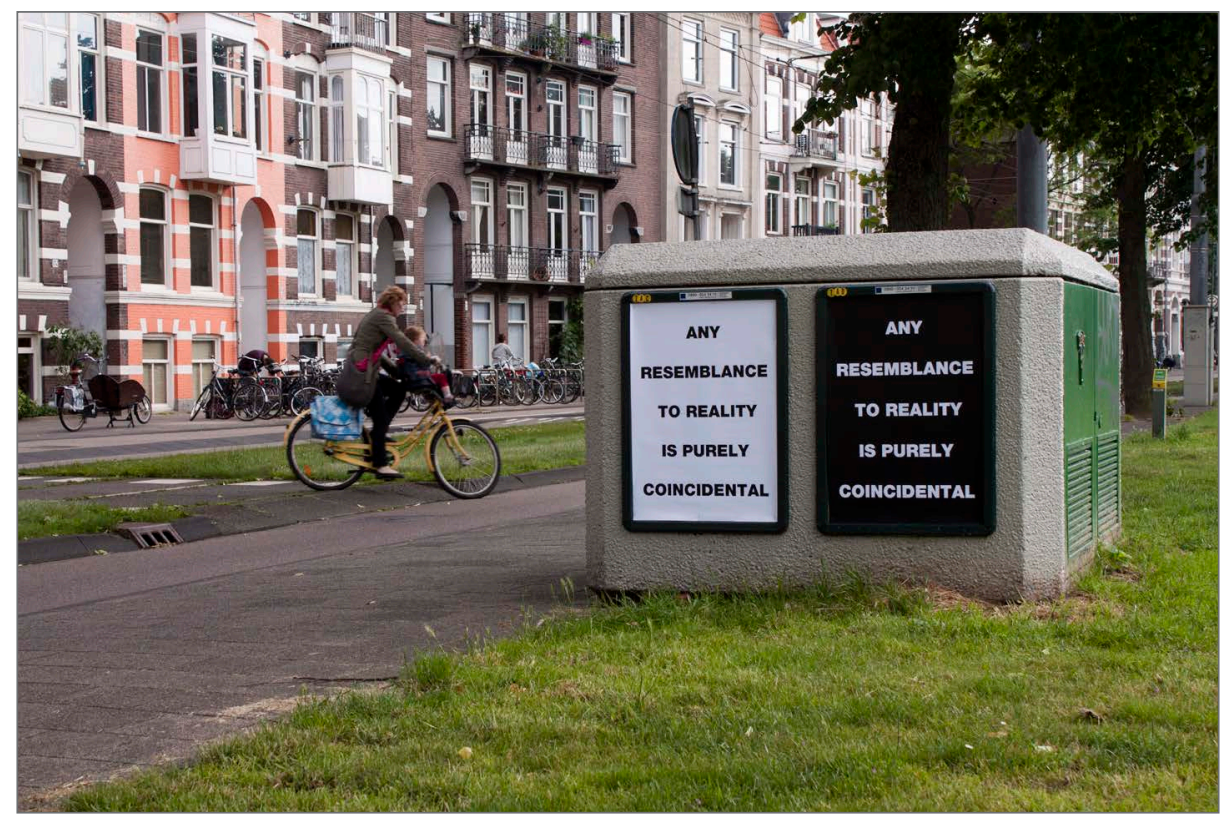

Figura 6.

\section{A MODO DE CONCLUSIONES}

Hemos visto cómo los artistas se sirven de estos espacios para llegar a "otros públicos". En este sentido, podríamos hablar de una pequeña grieta en el sistema desde donde adentrarse, desde las artes visuales, para generar trabajos de una naturaleza crítica que arrojan luz sobre cuestiones de nuestro día a día.

Los soportes propios de la publicidad se convierten en pequeños espacios para el arte desde dónde lanzar mensajes visuales de una naturaleza muy dispar a los que suelen acoger estos lugares, para así intentar llegar a un público mayor. Sin embargo, estas obras corren el riesgo de pasar desapercibidas, la publicidad se presenta como un gran depredador e introducirse en sus canales implica, en cierto modo, entrar en una especie de competición con ella, aunque no sea lo que el artista busque. En ocasiones, somos capaces de desarrollar la capacidad de anular imaginarios visuales que son emitidos a una velocidad vertiginosa, aprendemos, por supervivencia, a esquivar sus 
lanzas pero también, y de una forma absolutamente involuntaria, nos llegan y se introducen en nuestro subconsciente. Aún así, el arte desde este tipo de dispositivo es capaz de alcanzar un mayor número de personas que desde un centro de arte.

Desde los espacios habituales para el arte estas piezas también corren el peligro de desactivarse. Recordemos a Boris Groys cuando nos habla del museo como un cementerio, como un lugar de muerte repleto de cadáveres (Groys 2016). No podemos olvidar que un gran número de personas que acuden a un museo o una galería lo hacen siguiendo un comportamiento normalizado, del mismo modo que cuando van a un templo o a un cementerio. En el caso del centro de arte, asisten con una idea preconcebida, preparados para ver e interpretar una obra de arte. En esta línea, muchas piezas que se insertan en otros contextos ajenos al mundo del arte pueden llegar a adquirir un componente añadido, despojándoles de este aura que las dota la institución artística. Los públicos del mundo del arte, minoritarios en relación con los que acuden a otros contextos, pueden llegar a adquirir dos roles muy dispares. Unos acatan lo propuesto mediante exégesis o recursos apologéticos más complejos, mientras otros -más reducidos-, intentan una comprensión lúcida desde la que adoptan un posicionamiento crítico. El público del arte -en su mayoríacrece exponencialmente acudiendo a estos lugares como peregrinación cultural aunque los templos para el arte contemporáneo siguen estando todavía por explorar.

Estas propuestas artísticas, al salirse del espacio convencional asignado para el arte, pueden adquirir un potencial añadido pero también pueden correr el riesgo de ser desactivadas y perder toda su eficacia. Estos creadores, movidos por una necesidad de búsqueda de comunicación y de nuevos públicos, se adentran en estas estructuras propias del universo publicitario para, desde dentro, lanzar sus mensajes críticos al sistema que normalmente se sirve de estos medios.

\section{Referencias}

Baladrón Pazos, Antonio J., Esther Martínez Pastor \& Marta Pacheco Rueda, dirs. 2007.

Publicidad y ciudad: La comunicación publicitaria y lo urbano; Perspectivas y aportaciones. Sevilla: Comunicación Social.

Baudrillard, Jean. (1978) 2014. Cultura y simulacro. Traducción, Antoni Vicens y Pedro Rovira. Barcelona: Kairós. 
Brihuega, Jaime. 1995a, “Los gritos murales de Manolo Prieto". En Manolo Prieto y el toro Osborne, 30. Madrid: España Abierta.

- . 1995b. "Renau, de nuevo". En Josep Renau 1907-1982: Compromís i cultura, Exposició La Nau, Universitat de València, del 25 de septiembre al 11 de noviembre de 2007, 22-37. Valencia: Universitat de València.

Eguizábal Maza, Raúl. 2009. Industrias de la conciencia: Una historia social de la publicidad en España (1975-2009). Barcelona: Península.

Fernández Porta, Eloy. 2012. Eros: La superproducción de los afectos. Barcelona: Anagrama.

Foucault, Michel. (1975) 2002. Vigilar y castigar. Traducción Aurelio Garzón del Camino. Madrid: Siglo XXI

Gibbons, Joan. 2005. "Art invades and appropriates" En Art \& Advertising, 29-51. New York: I.B. Tauris.

Groys, Boris. 2016. Arte en flujo: Ensayos sobre la evanescencia del presente. Traducción, Paola Cortes Rocca . Buenos Aires: Caja Negra.

Gubern, Román. (1987) 1994. "Esplendor y miseria del cartel”. En La mirada opulenta: Exploración de la iconosfera contemporánea, 180-212. Barcelona: Gustavo Gili.

McQuail, Denis. (1991) 2010. Introducción a la teoría de la comunicación de masas. Traducción de Antonio J. Desmonts. Barcelona: Paidós.

\section{Notas}

1 Joan Gibbons en su libro Art \& Advertising (2005) nos adentra en cuestiones en las que arte y publicidad van de la mano, mostrándonos propuestas en las que artes visuales establecen acercamientos a la publicidad a la vez que pone sobre la mesa campañas publicitarias que se sirven de estrategias de las artes visuales.

2 Para ampliar información sobre el cartel véase Román Gubern: “Esplendor y miseria del cartel”, en La mirada opulenta: Exploración de la iconosfera contemporánea (1987).

${ }^{3}$ Raúl Eguizábal (2009) nos adentra en la historia social de la publicidad en España durante el siglo $X X$, analizando cuestiones vinculadas a la publicidad y sus mecanismos, la influencia que ésta ejerce en nuestras conductas y su evolución en el contexto español desde los años 70 hasta nuestros días.

${ }^{4}$ CERREC (Crear Es Resistir Resistir Es Crear) es una plataforma que se inicia en el año 2011 en España para apoyar y dar visibilidad a las reivindicaciones que impulsan las movilizaciones del $15 \mathrm{M}$ y denunciar la situación política, económica y social en que se encuentra inmerso el país en ese momento. CERREC se configura como un grupo heterogéneo y abierto compuesto por trabajadores de la cultura; la plataforma ha operado a través de redes sociales, principalmente mediante Facebook, desde donde se lanzaban y compartían propuestas en este sentido. Ha estado en activo sobre todo durante el año 2011.

${ }^{5}$ Estos son algunos ejemplos de obras que se inscriben en la línea del presente artículo, aunque no nos entraremos en detalle con nombres de más propuestas ya que nos centraremos en el arte español actual y estas obras sirven a modo de contextualzaición para adentrarnos en nuestro tema de estudio. Para más información véase "Art Ivades and Appropriates" en Gibbons, Art \& Advertising, 29-51. 
${ }^{6}$ Este artículo se contextualiza en el arte español actual, especialmente en un arte de vocación crítica. Podremos lanzar algunos nombres de artistas o algunas obras, pero no podremos detenernos en profundidad debido a la extensión aquí permitida.

${ }^{7}$ Sobre la vigilancia véase Michel Foucault: Vigilar y castigar (1975).

${ }^{8}$ Existen múltiples ejemplos de obras concebidas para ser mostradas en soportes de publicidad exterior, pero no nos detendremos en ellas por su extensión y magnitud. Por ese motivo, se ha elaborado un pequeño listado que sirve para representar este tipo de producción artística.

(Artículo recibido: 12-11-18; aceptado: 08-01-19) 